\title{
LETTER
}

\section{Power injectable peripherally inserted central catheters in the ICU: not only a question of flow}

\author{
Manuela Bonizzoli, Stefano Batacchi, Giovanni Zagli* and Adriano Peris \\ See related research by Pittiruti et al., http://ccforum.com/content/16/1/R21
}

In the previous issue of Critical Care, we read with interest the paper by Pittiruti and colleagues [1]. The work presents innovative approaches to the problem of venous access in intensive care, but characteristics of the study need to be discussed in order to correctly address the decision-making process at the base of the use of peripherally inserted central catheters (PICCs).

The study population consisted of adult and pediatric patients in whom power injectable PICCs were used, but the authors did not clarify whether every patient admitted to the intensive care unit (ICU) was automatically eligible for the placement of a PICC (a table summarizing population characteristics would help). To give important suggestions (for example, training and resource allocation) to those centers that are developing programs to improve the management of central venous catheters (CVCs), it would be interesting to know the total number of venous catheters inserted in the same period of the study.

Pittiruti and colleagues reported a virtual absence of deep vein thrombosis but only of symptomatic thrombosis. Ultrasound examination is performed only in the presence of clinical symptoms of suspected thrombosis. So the low incidence of symptomatic thrombosis is similar to that documented in a recent study from our group [2], and a higher asymptomatic thrombosis incidence documented by ultrasonography surveillance cannot be ruled out. The precise selection of the ratio of inner diameter of the vein to the outer diameter of the catheter could justify the good results obtained and should ensure the maintenance of a residual venous flow suitable to prevent pericatheter thrombosis.

\section{Authors' response}

Mauro Pittiruti and Giancarlo Scoppettuolo

Bonizzoli and colleagues address two very relevant issues: the appropriate indication of PICCs in the ICU and concern about their thrombotic risk. In regard to the first aspect, it is important to note that we reported our initial experience with a new venous access device by a retrospective investigation. In the first year (2010), 65 power injectable PICCs were inserted in our adult ICU patients [1], but in 2011, their number has almost doubled (118). Given that approximately 900 standard CVCs are inserted each year in our ICU (excluding Swan-Ganz and dialysis catheters), the use of the PICC as a central line is steadily increasing. However, since there are many obvious contraindications to PICCs (emergency situations, need for more than three lumens, local contraindications,

*Correspondence: giovanni.zagli@unifi.it

Anesthesia and Intensive Care Unit of Emergency Department, Careggi Teaching Hospital, Largo Brambilla 3, 50134, Florence, Italy chronic renal failure, and so on) [1], it seems unlikely that PICCs will completely replace CVCs in the ICU. Yet we recognize that, in the future, PICCs might prove to be an advantageous option in $20 \%$ to $30 \%$ of the ICU patients requiring a central line.

In regard to thrombosis, an appropriate prospective randomized trial is still needed to compare the actual incidence of asymptomatic/symptomatic thrombosis in CVCs with that in PICCs. Meanwhile, all we can do is to try to reduce the incidence of this complication by an appropriate choice of the vein (optimal ratio of vein to catheter diameter) [3,4] and an appropriate insertion technique (ultrasound venepuncture and proper 'central' position of the tip), as recommended by international guidelines $[5,6]$.

\section{Abbreviations}

CVC, central venous catheter; ICU, intensive care unit; PICC, peripherally inserted central catheter.

\section{Competing interests}

The authors declare that they have no competing interests. 
Published: 10 April 2012

\section{References}

1. Pittiruti M, Brutti A, Celentano D, Pomponi M, Biasucci DG, Annetta MG, Scoppettuolo G: Clinical experience with power injectable peripherally inserted central catheters in intensive care patients. Crit Care 2012, 16:R21.

2. Bonizzoli M, Batacchi S, Cianchi G, Zagli G, Lapi F, Tucci V, Martini G, Di Valvasone S, Peris A: Peripherally inserted central venous catheters and central venous catheters related thrombosis in post-critical patients. Intensive Care Med 2011, 37:284-289.

3. Nifong TP, McDevitt TJ: The effect of catheter to vein ratio on blood flow rates in a simulated model of peripherally inserted central venous catheters. Chest 2011, 140:48-53.

4. Meyer BM: Managing peripherally inserted central catheter thrombosis: a guide for best clinical practice. JAVA 2011, 16:144-147.
5. Campisi C, Biffi R, Pittiruti M: Catheter related central venous thrombosis: the development of a nationwide consensus paper in Italy. JAVA 2007 12:38-46.

6. Debourdeau P, Kassab Chahmi D, LeGal G, Kriegel I, Desruennes E, Douard MC, Elalamy I, Meyer G, Mismetti P, Pavic M, Scrobohaci ML, Levesque H, Renaudin JM, Farge D: 2008 SOR guidelines for the prevention and treatment of thrombosis associated with central venous catheters in patients with cancer: report from the working group. Ann Oncol 2009, 20:1459-1471.

doi:10.1186/cc11258

Cite this article as: Bonizzoli $\mathrm{M}$, et al.: Power injectable peripherally inserted central catheters in the ICU: not only a question of flow. Critical Care 2012, $16: 422$ 